\title{
O ASSOCIATIVISMO RURAL COMO ESTRATÉGIA DE DESENVOLVIMENTO PARA A AGRICULTURA FAMILIAR
}

\author{
Rural Associativism as a Development Strategy for a Family Farming
}

\begin{abstract}
Acssuel de Sousa Lisboa*
Fernanda Viana de Alcantara **

* Acadêmico do Programa de Pós-graduação em Geografia- PPGeo/UESB. - E-mail: acssuel_lisboa@hotmail.com.

** Professora do Programa de Pos-Graduaçao em Geografia- PPGeo/UESB. E-mail: falcantara17@hotmail.com.
\end{abstract}

Recebido em 09/03/2019. Aceito para publicação em 20/03/2019.

Versão online publicada em 26/04/2019 (http://seer.ufrgs.br/paraonde)

\begin{abstract}
Resumo:
O objetivo do presente trabalho é discutir o papel do associativismo rural na articulação dos agricultores familiares para a busca de estratégias que garantam melhorias em suas condições de vida. Inicialmente, apresenta-se uma discussão relacionada à produção e dinâmica da agricultura familiar no Brasil ao longo do tempo. Em seguida, é refletido sobre a relação entre agricultura familiar e políticas públicas, em especial, o Programa Nacional de Fortalecimento da Agricultura Familiar (PRONAF), enfatizando a importância do mesmo para essa categoria. Por fim, faz-se uma abordagem da questão do associativismo rural como prática significativa para viabilização da consciência dos direitos e deveres dos agricultores familiares e do suprimento das suas necessidades básicas que muitas vezes os são negados. Processo que influencia consideravelmente no processo de produção e reprodução da agricultura familiar. Destarte, para basilar a análise, entrelaçadas visões de autores como Schneider e Niederle (2010), Abramovay (1997), Junquera e Lima (2008), Mattei (2005), Abramovay e Veiga (1999), Vilella (2006), Ganança (2006), entre outros.
\end{abstract}

Palavras-chave: Associativismo Rural; Agricultura Familiar; Políticas públicas; Pronaf.

\begin{abstract}
:
The objective of the present work is to discuss the role of rural associativism in the articulation of family farmers to search for strategies that guarantee improvements in their living conditions. Initially, a discussion is presented regarding the production and dynamics of family agriculture in Brazil over time. Then, it is reflected on the relationship between family agriculture and public policies, in particular the National Program for Strengthening Family Agriculture (PRONAF), emphasizing the importance of the same for this category. Finally, an approach is taken to the issue of rural associativism as a meaningful practice to enable the awareness of the rights and duties of family farmers and the supply of their basic needs, which are often denied. Process that considerably influences the process of production and reproduction of family farming. In order to base the analysis, interwoven visions of authors such as Schneider and Niederle (2010), Abramovay (1997), Junquera and Lima (2008), Mattei (2005), Abramovay and Veiga (1999), Vilella 2006), among others.
\end{abstract}

Key-words: Rural Associations; Family Farming; Public Policy; Pronaf.

\section{Introdução}

O presente trabalho lança o seu olhar para a dinâmica da agricultura familiar, em especial as suas articulações por meio do associativismo rural como estratégia que viabilize melhorias no seu modo de produção e reprodução social. Sendo a prática associativa, entendida como resultado de constantes lutas dos pequenos agricultores frente às complexas e excludentes relações existente na sociedade brasileira.

Na histórica e difícil conjuntura do campo brasileiro a expressão agricultura familiar ganha força 
em meados da década de 1990 e o agricultor familiar traz uma nova dinâmica para o espaço rural caracterizando mínimas, porém significativas, mudanças que foram e são resultantes das lutas e movimentos da sociedade organizada, principalmente na perspectiva de buscar melhorias para o pequeno produtor. Assim, mesmo em uma sociedade marcada por tradições latifundiárias, a agricultura familiar vem conseguindo se desenvolver consideravelmente, conquistando ao longo do tempo, ainda que de forma vagarosa, um espaço a partir de construções que envolvem relações politicas, econômicas, coletivas e culturais.

A consolidação e reconhecimento formal da agricultura familiar se deram mediante vários fatores que pressionaram o estado, tendo como resultado a criação de políticas públicas direcionadas que têm a [...] "finalidade de implementar determinadas ações objetivando promover o crescimento e o desenvolvimento de um setor econômico ou de um lócus geográfico" (RUA, 2005), nesse caso, visando o desenvolvimento e interação da agricultura familiar. Destarte, as políticas públicas, em especial o Programa de Fortalecimento da Agricultura Familiar (PRONAF), estão intrínsecas no processo de mudança do rural brasileiro, no que diz respeito à agricultura familiar.

Nesse contexto, a prática associativa no espaço rural aparece como peça fundamental não só na promoção do acesso às politicas públicas, mas também na conscientização no que diz respeito aos direitos e deveres básicos que devem ser assegurados ao agricultor familiar e que na maioria das vezes os são negados.

Portanto, apesar das limitações que enredam a pratica associativa, as características e dimensões da mesma são primordiais na construção de um novo modelo social e político que vai de encontro com a perspectiva do desenvolvimento social, concebido pela relação baseada nos arranjos de articulação, organização e participação do pequeno agricultor pautado em descentralizar os poderes e decisões, o que, simultaneamente, proporciona o fortalecimento direto tanto da prática associativa como do projeto de desenvolvimento no país.

\section{A agricultura familiar no Brasil: uma breve abordagem histórica}

A discussão acerca da agricultura familiar vem se tornando cada vez mais visível nos últimos tempos, inclusive em debates acadêmicos, fator que se consolida como importante no processo de reconhecimento social, econômico e cultural dessa categoria plural. Entretanto, não se pode negar que, apesar de certos avanços, a mesma ainda enfrenta diversos problemas e desafios relacionados com a falta de reconhecimento político.

Portanto, a análise do surgimento da produção social dessa categoria e essencial para compreensão das dinâmicas que configuram o espaço rural. Contudo, a análise se torna complexa, uma vez que se trata de sujeitos e elementos sociais que se produzem e reproduzem constantemente. Nesse sentido, a definição e conceituação do termo agricultura familiar, justamente por sua dinâmica e pluralidade, envolvem confusões teóricas, o que reforça a necessidade de um debate abrangente que se considere as especificidades espaciais.

É fato que em quase todo o processo histórico do espaço rural brasileiro, somente a agricultura de base patronal era considerada como vetor de desenvolvimento do campo no país, todo os olhares e investimentos se voltavam para esse segmento de produtividade econômica e os pequenos produtores rurais permaneciam totalmente às margens do processo, subordinados ao desemprego e a exploração.

Nesta conjuntura de desigualdade, por meio de lutas coletivas e organizadas via sindicatos e movimentos sociais, os trabalhadores rurais conseguem, mínima, porém significativa notoriedade frente às classes dominantes. São reconhecidos enquanto categoria social agricultura familiar, especificamente em meados da década de 1990, como um novo ator, trazendo uma nova dinâmica para o espaço rural.

Para0nde!?, Porto Alegre, v.11, n.1, p.17-28, 2019. http://seer.ufrgs.br/paraonde

Edição Especial: "Geografia e transformações socioespaciais: dinâmicas agrárias e políticas do desenvolvimento regional" 
Nesse contexto, Panzutti e Monteiro 2015 destacam:

\begin{abstract}
Os agricultores familiares começaram a entrar na pauta do governo somente após a reforma da Assembleia Nacional Constituinte, em 1987. Em virtude do contexto macroeconômico da reforma do Estado, a partir da década de 90 surgiram as políticas públicas destinadas a esse segmento motivadas pela crescente necessidade de intervenção estatal face à crescente exclusão social e o fortalecimento dos movimentos sociais rurais. (PANZUTTI; MONTEIRO, p. 03) citação citação citação citação citação citação citação citação citação citação citação citação (AUTOR, ano, pg).
\end{abstract}

A recente conquista surge por meio de pressões dos pequenos agricultores articulados, principalmente, em movimentos sindicais, com a necessidade de auxílio estatal frente às distorções encontradas no campo, relacionadas à crescente exclusão social. Esse processo visava buscar, principalmente, melhorias para o pequeno produtor ou produtor de baixa renda, como eram denominados anteriormente pelo olhar discriminador e dominante, como afirmado por Schineider e Niederle (2010):

A rigor, antes da década de 1990, a própria referencia à agricultura familiar no Brasil era quase inexistente, uma vez que os termos usualmente utilizados para qualificar essas categorias sociais eram os de pequeno produtor, produtor de subsistência ou de baixa renda. Em decorrência das lutas do movimento sindical por crédito, melhoria de preços, formas de comercialização diferenciadas, implementação da regulamentação constitucional da previdência social rural, entre outras, essas denominações foram cedendo espaço para a de agricultura familiar, que deslocou igualmente a própria identidade sindical em torno da noção de trabalho rural. (SCHNEIDER; NIEDERLE, 2010, p. 990).

Destarte, essa categoria social surge de forma dinâmica no processo de (re)configuração do espaço rural por intermédio das relações sociais e econômicas que se tornam necessárias no decorrer do tempo, influenciadas e influenciando os processos sociais, econômicos e culturais do país.

A agricultura familiar possui características simples e variadas que definem parte da sua dinâmica territorial, estabelecidas por vínculos, como o próprio nome já diz afetivo familiar, no qual a produção e a renda gira dentro da própria família sendo viabilizada para o bem estar de todos os componentes, uma vez que não há separação entre trabalho e gestão, sendo responsabilidade de todos da família. Essa tendência, ou seja, estratégias de organização dos agricultores familiares, atualmente, depois de preconceitos, no sentido radical da palavra, é reconhecido por sua eficiência e racionalidade.

A produção da agricultura familiar, de forma geral, se desenvolve e caracteriza de maneira distinta em cada país. Com base em diversos estudos, afirma-se que o Brasil se difere consideravelmente de outros países, principalmente os de primeiro mundo, onde a produção familiar corresponde a uma boa parcela da economia. Já no Brasil, a agricultura é marcada pelo modelo bimodal (Cordeiro, 1996), no qual há áreas de produção moderna e áreas de produção tradicional, com certo desequilíbrio que causa contradições no meio rural, uma vez que no sistema capitalista, a agricultura familiar, por sua baixa produtividade, não possui importância para o desenvolvimento econômico do país.

Contudo, é importante perceber que a baixa produtividade dessa categoria não pode ser rotulada como incapacidade, deve-se olhar para o processo temporal que ela está inserida e entender que isso é reflexo da falta de investimentos, ou seja, da falta de reconhecimento social, econômico e cultural por parte dos gestores.

ParaOnde!?, Porto Alegre, v.11, n.1, p.17-28, 2019. http://seer.ufrgs.br/paraonde

Edição Especial: "Geografia e transformações socioespaciais: dinâmicas agrárias e políticas do desenvolvimento regional" 
Destaca-se que, apesar das dificuldades enfrentadas no país, a agricultura familiar se encontra, em algumas regiões, sendo desenvolvida de forma dinâmica e flexível, sempre buscando estratégias para se reproduzir dentro do cenário socioeconômico em diferentes escalas. Segundo Abramovay (1997):

\begin{abstract}
Mas é interessante observar que mesmo em países com forte peso de tradição latifundiária, ao lado de milhões de unidades que podem ser consideradas a justo título como precárias, pequenas, gerando uma renda agrícola extremamente baixa, desenvolvese também um segmento familiar dinâmico capaz de integrar-se ao sistema de crédito, cujo comportamento econômico difere da famosa e tão estudada aversão ao risco, que adota a inovação tecnológica e integra-se a mercados competitivos. (ABRAMOVAY, 1997, p. 04).
\end{abstract}

0 autor frisa muito bem a força e dinâmica da agricultura familiar. Mesmo em um país que ainda carrega grande peso referente a tradicionais problemas fundiários e agrários, ela, ainda que de forma heterogênea, consegue buscar meios que possibilitam certa integração no palco socioeconômico do Brasil. Entretanto, é notório que esse processo de desenvolvimento depende de vários fatores ligados ás características da categoria, relacionado às unidades de produção, à capacidade dos agricultores e do contexto de apoio, ou seja, do suporte socioeconômico estabelecido pelos, por meio, dos poderes públicos.

De forma geral, mesmo que percebido por poucos e em espaços reduzidos, pode-se afirmar que a agricultura familiar representa importante papel na economia do país. Para Testa (2010):

As características, o modo de funcionamento e as contribuições que a agricultura familiar (AF) pode dar ao desenvolvimento de um país geralmente é tema pouco conhecido, mesmo em universidades, nas instituições de pesquisa e extensão rural e nos governos. Dos muitos campos em que ela pode contribuir, vamos destacar o econômico, o sóciocultural, o ambiental, o de segurança alimentar e o de segurança nacional, através da ocupação e defesa do território. (TESTA, 2010, p.1).

A produção familiar em todo seu conjunto estrutural contribui em diversos campos do país: na regulação e redução dos preços de alimentos, transferência de renda para os outros segmentos (por sua organização familiar), segurança alimentar e mesmo em porções marginalizadas eles conseguem produzir consideravelmente. A mesma produz mais da metade dos alimentos que são consumidos pela população brasileira, participa na geração de emprego, geração e distribuição de renda, diminuição do êxodo rural e contribui, também, para a segurança alimentar.

A categoria vem conquistando ao longo do tempo, um espaço por intermédio de construções que envolvem relações politicas, coletivas e culturais. Essa conquista se dá pela criação de políticas públicas atreladas ao seu processo de reconhecimento enquanto categoria social, que tem possibilitado certo desenvolvimento da agricultura familiar. Contudo, isso deve ser visto como um processo desenrolado historicamente por grupos que na maioria das vezes são inferiorizados e que querem conquistar sua notoriedade frente às outras classes.

\title{
2.1 Alguns apontamentos a respeito da relação entre agricultura familiar e o PRONAF
}

Como mencionado anteriormente, na década de 1990 começa-se a perceber uma grande mudança no cenário rural do Brasil, dá inicio à concretização de um interesse considerável à nova categoria do espaço rural, a agricultura familiar. Ou seja, "na última década está havendo uma tentativa de resignificar o conceito de agricultor familiar e de tornar esta categoria central num modelo de

Para0nde!?, Porto Alegre, v.11, n.1, p.17-28, 2019. http://seer.ufrgs.br/paraonde

Edição Especial: "Geografia e transformações socioespaciais: dinâmicas agrárias e políticas do desenvolvimento regional" 
desenvolvimento."(OLALDE; PORTUGAL, 2011, p.1).

De modo geral, a partir da década de 1990 que demarca um período no qual começa a ocorrência da "democratização" de políticas voltadas para as demandas sociais, inicia-se uma tentativa de valorização da agricultura familiar que vinha se apresentando com importantes resultados, mesmo com todas as adversidades e fragilidades marcada pela desigual modernização da agricultura. Nesse contexto, a valorização ocorre através de políticas especificas, relacionadas a instrumentalização das atividades para que gere empregos, aumento e distribuição de renda, e assim contribuindo para o desenvolvimento local.

O desenvolvimento e reconhecimento formal da agricultura familiar, mais uma vez, se deram por meio de vários fatores que desencadearam lutas constantes na qual teve, e, mesmo que de forma reduzida, esta tendo, como resultado, a criação de politicas publicas que tem [...] "finalidade de implementar determinadas ações objetivando promover o crescimento e o desenvolvimento de um setor econômico ou de um lócus geográfico" (RUA, 2005), nesse caso, visando a ampliação e interação social, econômica e cultural dessa categoria.

Somente em meados da década de 1990 que as políticas públicas voltadas para o meio rural e, especificamente, para a agricultura familiar, começam a aparecer e receber uma significação, crescendo a participação no PIB do país, o que acaba gerando renda, mercado e emprego para a categoria.

Segundo Junqueira e Lima (2008):

[...]as políticas públicas voltadas à promoção da agricultura familiar seriam capazes de diminuir algumas das dificuldades históricas para o desenvolvimento do setor como: a baixa capitalização, a dificuldade de acesso ao crédito, e o acesso aos mercados modernos pela adoção de novas tecnologias. Superadas tais dificuldades o setor poderia então contribuir para a economia local e para o desenvolvimento das sociedades onde estão inseridos.(JUNQUERA; LIMA, 2008, p.03)

Os autores apontam, de forma geral, as vantagens, ou seja, a importância das políticas públicas voltadas para a agricultura familiar na perspectiva de superação das dificuldades enfrentadas, contribuindo assim para o melhoramento das comunidades e respectivamente do local em que vivem.

Nessa perspectiva, imbricado à agricultura familiar, destaca-se o Programa Nacional de Fortalecimento da Agricultura Familiar - PRONAF, que foi e continua sendo fundamentalmente importante para o desenvolvimento da categoria, uma vez que por meio desse programa que ela tem conquistado certa notoriedade no cenário social, econômico e cultural do país, de modo que tal política foi a responsável pela consolidação do reconhecimento dos pequenos produtores enquanto categoria social agricultura familiar. Segundo Lauro Mattei 2005, o PRONAF:

teve, desde sua criação, o intuito de criar e fortalecer 'as condições objetivas para o aumento da capacidade produtiva, a melhoria da qualidade de vida e o pleno exercício da cidadania no campo por parte daqueles que integram o regime da agricultura familiar'. (MATTEI, 2005, p. 04)

O PRONAF, criado em 1995 através da Resolução n 2.191 do Banco Central do Brasil como primeiro programa voltado para a agricultura familiar, regulamentado pelo Decreto Presidencial, $\mathrm{n}^{\circ}$ 1.946 de 28-06-1996 (Carvalho, 2018), proporciona uma especifica linha de crédito de custeio para financiar esse segmento influenciando de forma significativa no seu desenvolvimento, mediante a inserção de novos elementos que tem por objetivo a melhoria da produção e reprodução desse

Para0nde!?, Porto Alegre, v.11, n.1, p.17-28, 2019. http://seer.ufrgs.br/paraonde

Edição Especial: "Geografia e transformações socioespaciais: dinâmicas agrárias e políticas do desenvolvimento regional" 
segmento, uma vez que, desde o seu início têm os recursos aplicados no mesmo tem aumentado significativamente. Em 1996 foram destinados aproximadamente R\$ 650 milhões e em 2012 este montante alcançou o valor de quase $\mathrm{R} \$ 16$ bilhões (valores correntes), o que significa um crescimento superior a 20 vezes. No Plano Safra da Agricultura Familiar 2013/2014, o valor disponibilizado saltou para R\$21 bilhões (Brasil, MDA, 2013).

O programa, inicialmente, se dividia em três linhas: Pronaf Crédito, Pronaf Infraestrutura e Pronaf Capacitação. 0 primeiro, linha concebida desde o início do programa, se destaca como principal em termos de recursos, com mais de $90 \%$ do total. 0 segundo, passa a ser deliberado na perspectiva territorial a partir do ano de 2003. E o terceiro, mesmo com sua nítida relevância, tem perdido importância no âmbito de investimento nos últimos anos. (Silva, 2012)

Nessa perspectiva, através do INCRA/FAO estabeleceu diferentes grupos de agricultura familiar: consolidada (1,5 milhão de estabelecimentos); transição (2,5 milhão de estabelecimentos) e periférica (2,5 milhões de estabelecimentos). (Panzutti e Monteiro, 2015). Porém, as iniciais ações e organizações definidas para programa não garantiam o objetivo esperado.

Segundo Panzutti e Monteiro (2015):

A legislação do PRONAF no que se refere à definição dos beneficiários mudou com o passar dos anos mudando também a definição dos beneficiários considerados como agricultores familiares. Desta forma, 15 grupos são contemplados pelo programa, com os seguintes requisitos: a) proprietários, assentados, posseiros, arrendatários, parceiros ou meeiros que utilizam mão de obra predominante familiar e tenham até 2 empregados permanentes; b) não detenham qualquer título e áreas superiores a 4 módulos fiscais; c) tenham renda bruta familiar com no mínimo $80 \%$ dela proveniente da agropecuária e não agropecuária desenvolvida no estabelecimento; d)residam na propriedade ou em local próximo.(PANZUTTI; MONTEIRO, 2015, p. 05).

A partir da análise dos critérios estabelecidos pelo PRONAF, pode-se perceber as distorções dentro dele. Um dos problemas encontrado está relacionado com o item C $(80 \%$ da renda bruta anual devem ser proveniente da agropecuária e não agropecuária desenvolvida no estabelecimento), assim:

[...] observa-se a tendência do programa excluir os agricultores e as regiões mais pobres que não conseguem sobreviver unicamente da exploração agropecuária e que necessitam complementar a renda com outras fontes - aposentadorias e atividades não agrícolas. (PANZUTTI; MONTEIRO, 2015, p. 05).

Observa-se que a proposta do programa apresenta contradições com relação ao seu objetivo inicial, dando maiores possibilidades a uma parcela dos agricultores familiares, à parcela mais estruturada. A questão do acesso ao mercado é outro fator deficitário enfrentado pela agricultura familiar, uma vez que o desempenho da produção familiar vai depender diretamente desse acesso, porem a sua inserção no mercado é dificultada, principalmente, pela incerteza, pelo risco de perda da produção que está ligado a uma questão natural, às características climáticas.

Essa instabilidade que perpassa o Pronaf e característica de muitas políticas públicas, de modo que, como salientado por Pochman (2003), a criação de uma política pública está imbrincada a um mar de certezas, pois compreende um emaranhado de elementos institucionais, governamentais e não governamentais, as barreiras orçamentarias, além da fluidez das relações sociais que está intrínseca a produção e reprodução do espaço geográfico. Nesse contexto, o Pronaf teve que passar por diversas alteração até chegar no atual nível de operacionalidade que, diga-se de passagem, ainda está longe do ideal.

Para0nde!?, Porto Alegre, v.11, n.1, p.17-28, 2019. http://seer.ufrgs.br/paraonde

Edição Especial: "Geografia e transformações socioespaciais: dinâmicas agrárias e políticas do desenvolvimento regional" 
Apesar de toda instabilidade, o programa trouxe mudanças indubitáveis para o agricultor familiar e concomitantemente para o espaço rural brasileiro, principalmente, como apontado por Abramovay e Veiga (1999), no que se refere à legalidade de uma nova e inédita relação entre o segmento bancário e a agricultura familiar. Desse modo, as iniciativas e ações desenvolvidas desencadeiam transformações que produzem um novo cenário no país, especialmente na dinâmica do rural.

Contudo, as politicas públicas para a agricultura familiar devem ser analisadas nas suas amplitudes, considerando as diversas variáveis relacionadas à realidade concreta da agricultura familiar, pois tanto as vantagens como desvantagens dependem das reais condições do espaço na qual estão inseridos. Caso contrário, dentro da escala agricultura familiar, serão mais algumas das tradicionais politicas públicas do país, atendendo apenas uma parcela dos sujeitos, os mais favorecidos.

Nesta perspectiva, como mencionado anteriormente, as conquistas sociais que envolvem as camadas mais frágeis, em especial os trabalhadores rurais, foram desencadeadas por meio de pressão dos mesmos frente ao estado, dentro de um processo organizacional de articulação coletiva e participação social fomentando a necessidade de políticas verticalizadas. As organizações não governamentais, associações rurais, sindicatos, movimentos sociais, etc. foram peças fundamentais nesse processo. Assim, destaca-se aqui o associativismo rural como prática essencial no contexto da produção e reprodução da agricultura familiar.

\section{O associativismo rural como estratégia de integração para o agricultor familiar}

É fato os pesos e privações enfrentadas pelos agricultores familiares ao longo do tempo, resultando em déficits social, econômico e cultural enquanto reflexo das relações de desigualdade inerente ao sistema capitalista. Entretanto, como já apontado, nas últimas décadas essa categoria tem conseguido certa notoriedade frene às classes dominantes, principalmente, por meio da união de esforços dos agricultores familiares via organizações coletivas, em especial, o associativismo que surge no meio rural como estratégia de fortalecimento para esse grupo.

0 termo e a definição de associativismo, por sua pluralidade, envolvem complexidades que devem ser analisadas cuidadosamente. 0 termo "associação" é bem comum e, de forma geral, significa junção, união, relação de algo ou alguém. Já dentro do Código Civil e da Lei de Registros Públicos é definida "como uma pessoa jurídica de direito privado, institucionalizada, devidamente registrada nos cartórios de registro civil de pessoas jurídicas, constituída livremente pela união de pessoas em torno de uma finalidade não econômica ou não lucrativa." (GANANÇA, 2006, p.31). Porém, na realidade as associações não se restringem a essa definição, uma vez que, mesmo de maneira equivocada, o associativismo seja quase sempre relacionado com atividades econômicas, se trata de um processo social que envolve diferentes segmentos da sociedade carregados de diversidades.

Nesse contexto, destacam-se aqui as associações criadas no espaço rural pelo segmento da agricultura familiar com o intuído de desenvolver o associativismo na perspectiva do suprimento das demandas do agricultor familiar por meio do conhecimento dos seus direitos e deveres básicos que, na maioria das vezes, são negados.

0 associativismo rural consiste em uma atividade organizacional coletiva que tem como finalidade conquistar benefícios comuns para os sujeitos que a compõe, sem nenhum fim lucrativo. As práticas organizacionais coletivas no campo se constituem como importante vetor no que diz respeito à percepção e busca de direitos. Assim, pode-se afirmar que essa prática associativa é fruto da constante luta social no espaço rural por melhores condições de vida, por um reconhecimento que proporcione certa integração no cenário social, econômico e cultural.

As associações se encontra de forma expressiva no meio rural brasileiro, principalmente sendo constituídas por agricultores familiares que começam a caminhar para percepção de si enquanto

Para0nde!?, Porto Alegre, v.11, n.1, p.17-28, 2019. http://seer.ufrgs.br/paraonde

Edição Especial: "Geografia e transformações socioespaciais: dinâmicas agrárias e políticas do desenvolvimento regional" 
sujeito social que tem deveres e direitos mínimos que devem ser assegurados para sua permanência no espaço rural.

Nessa perspectiva, para Toniasso, Souza, Brum e Figueiredo (2007) :

As associações de agricultura familiar que têm se formado em todos os estados brasileiros se constituem como organizações sociais ou de economia social que, como afirma Pimenta e outros (2006, p.84), são aquelas que desenvolvem atividades econômicas caracterizadas pela gestão democrática e autônoma das organizações e pela primazia das pessoas sobre o lucro. Essas atividades seriam exercidas por sociedades cooperativas, organizações mutualistas e associações. (FIGUEIREDO et al ,2007, p. 3)

O associativismo se desenvolve social, democrática e voluntariamente, ou seja, sem fins lucrativos diretamente, porém, nesse caso, visa a estabilidade e inserção do pequeno agricultor no campo e no mercado econômico, reforçando assim suas territorialidades. Sperry (2003) destaca que com a criação dessas associações no meio rural, as lavouras e produções de agricultura familiar apareceram com maiores possibilidades. "A exploração da forma coletiva do trabalho surgiu como fonte de renda e experimentação tecnológica para tornar sustentáveis algumas atividades de produção coletiva dessas associações".

As formas coletivas de trabalho no espaço rural se expressam com maior abrangência nos municípios que possui predominância da pequena propriedade privada, no qual se desenvolve a agricultura de cunho familiar. A dificuldade de produzir na propriedade, por consequência (como no caso da região nordeste), das condições climáticas não favoráveis e, principalmente, por falta de incentivos que possibilite sua reprodução, faz com que esses sujeitos busquem formas de articulação que permita pensar e buscar os seus direitos que podem garantir melhorias nas suas condições de vida. Essas formas de articulação se expressam significativamente no país, uma vez que:

Necessário se torna estimular a capacidade de organização dos pequenos agricultores brasileiros, provocando a criação de atividades conjuntas, despertando o associativismo para, de uma forma conjunta, enfrentarem os seus problemas. Para tal, os organismos nacionais de desenvolvimento rural ou de política agrícola devem procurar orientar, estimular e conscientizar o pequeno produtor para aquisição de bens e insumos em forma associativista, mostrandolhes que conscientes, organizados e participativos poderão auxiliar na consecução de seus problemas prioritários. (VILLELA, 2006, p.1).

É possível refletir sobre as lutas e desejos do pequeno agricultor juntamente com a importância da associação, da participação, organização e consciência como caminho para tais conquistas, uma vez que as batalhas se desencadeiam na perspectiva de estruturação social e de formas de territorialidade. Assim, para reforçar a sua representatividade, é fundamental o estimulo da capacidade organizacional e participativa dos agricultores.

Dentro dessa dinâmica, é importante destacar que o início do surgimento de associações no espaço rural se dá por intermédio de "exigências" governamentais. No processo de operacionalização das políticas públicas voltadas para o agricultor familiar, as mesmas traziam o requisito de exigência de uma entidade associativa, pregando a necessidade da organização e institucionalização dos produtores rurais para a garantia e o facilitar da implementação das ações sociais. Nota-se que esse modelo vem carregado de interesses político partidário que acabam deixando o agricultor familiar dependente de certas ações e acreditando que o associativismo se restringe apenas a busca de interesses individuais, emergentes e mateias, fator que se apresenta como um dos principais desafios

Para0nde!?, Porto Alegre, v.11, n.1, p.17-28, 2019. http://seer.ufrgs.br/paraonde

Edição Especial: "Geografia e transformações socioespaciais: dinâmicas agrárias e políticas do desenvolvimento regional" 
enfrentados pela prática.

Entretanto, apesar de todo o jogo político, essa "exigência", em muitos casos, se transforma em estimulo, mediante o desencadeamento do surgimento de inúmeras associações rurais que buscam a inclusão do agricultor familiar nos processos social, produtivo e cultural, mesmo com as limitações que enredam a prática.

0 associativismo compreende diversos princípios que necessitam ser articulados para o alcance de resultados positivos e consideráveis. Alguns dos principais papéis que devem ser desempenhados pelas associações e que também se constituem como desafio, é o informativo e de orientação trabalhados na perspectiva da conscientização dos direitos, deveres e do verdadeiro papel das associações como condicionantes para autonomia e autogestão das mesmas. Sendo esses últimos primordiais na consolidação do real associativismo, desenvolvido no contexto democrático e de emancipação dos sujeitos envolvidos.

A prática associativa desenvolvida nessa perspectiva possibilitarão condições para que o agricultor se desenvolva em seu meio, pois:

A agricultura em grupo proporciona condições para obtenção de resultados na economia de escala, na participação e capacitação, na utilização de máquinas e equipamentos, na oferta de trabalho, na preservação do meio ambiente, na estabilidade e renda, assim como, na utilização dos escassos serviços públicos. (VILLELA, 2006, p.1).

A agricultura familiar encontrará capacidades referentes à produtividade e inserção econômica, e, também, na digna vivência social, através de qualificações e informações acerca dos principais assuntos que derivam das atividades e demandas da comunidade e da consciente busca de estratégias para supri-las. De certo modo, a prática, mediante a articulação, proporciona formas e estímulos de vivência no seu meio que, na maioria das vezes, foi visto como precário e sem condições de manter e muito menos de desenvolver o agricultor familiar, esvaziando-se consequentemente.

Ao analisar o contexto histórico do rural brasileiro é correto afirmar que as mudanças relacionadas ao pequeno agricultor ocorreram, inicial e principalmente, por intermédio de ações governamentais, ou seja, de políticas públicas. E o conjunto de relações que reivindicam direitos sociais do pequeno produtor rural se constitui como essencial no processo de imposição das necessidades de políticas públicas competentes que atendam como suporte as demandas do trabalhador rural, mesmo que essa busca ainda não tenha se concretizado de maneira completa.

Nessa quadra, é fato que as políticas públicas direcionadas a agricultura familiar são relativamente escassas, e o pouco que existe, na maioria das vezes, o acesso se torna dificil, principalmente pela falta de conhecimento e informação. Direcionalmente, o associativismo possibilita informação e o conhecimento sobre tais políticas públicas, as formas de enquadramento e de conquistas às mesmas.

Contudo, o associativismo funciona como espaço de articulação e reflexão sobre variadas ações que buscam o desenvolvimento social, econômico e cultural, a permanência do agricultor familiar no meio em que vive, através, principalmente, de políticas públicas e através da consolidação de planos estratégicos para o desenvolvimento dessa categoria. (LISBOA; ALCANTARA, 2015).

Dessa maneira, mesmo cercados de desafios e instabilidades antagônicas, as características e dimensões do associativismo são primordiais na construção de um novo modelo social e político que vai de encontro com a perspectiva do desenvolvimento social, concebido pela relação baseada nos arranjos de articulação, organização e participação pautados em descentralizar os poderes e decisões, o que, simultaneamente, proporciona o fortalecimento direto tanto da prática associativa como do projeto de desenvolvimento rural no país.

Para0nde!?, Porto Alegre, v.11, n.1, p.17-28, 2019. http://seer.ufrgs.br/paraonde

Edição Especial: "Geografia e transformações socioespaciais: dinâmicas agrárias e políticas do desenvolvimento regional" 


\section{Considerações finais}

As relações que ocorrem no espaço rural brasileiro, principalmente relacionado a agricultura, é de grande complexidade, uma vez que esse espaço apresenta diversificadas formas de produção, organização e estrutura social, relacionadas a questões econômicas, políticas e culturais que se dimensionam constantemente. Fator que reforça a necessidade de analises que considerem a heterogeneidade do espaço geográfico dentro da totalidade.

Nesse contexto, a agricultura familiar possui um importante papel no cenário do rural brasileiro e também nos processos econômicos e culturais do país. Assim, a discussão acerca da agricultura familiar vem se tornando cada vez mais importante ao longo do tempo, uma vez que a categoria possui um significativo papel na sociedade.

É fato que a agricultura familiar ainda carece de maior reconhecimento no que diz respeito a suas contribuições nos arranjos sociais, desafio que se consolidou no processo histórico do país com relação à complexa questão agrária brasileira. Porém, não se pode negar que, através de lutas organizadas e com o surgimento de políticas públicas especificas, a agricultura familiar conseguiu um mínimo, porém significativo, desenvolvimento referente ao seu reconhecimento e inserção socioeconômica e também cultural.

Nesse processo de mudanças, é notório que o associativismo rural influenciou e influencia de forma positiva no desenvolvimento do agricultor familiar, possibilitando a sua articulação coletiva que permite, por intermédio da organização e do foco a bens comuns de direito, a garantia de benefícios mínimos, entretanto essenciais à vivencia, reprodução e permanência no espaço em que vive.

É notório também que a prática associativa no espaço rural ainda enfrenta diversos desafios que precisam ser superados para que se atinja melhores resultados. Destaca-se, como principal desafio e que perpassa influencia diversos outros problemas, a dificuldade de estabelecer uma consciência política que garanta o associado perceber que o associativismo é muito mais amplo e não se restringe somente a busca de interesses emergente, práticos e individuais.

Nessa direção se torna essencial o estimulo da capacidade organizativa do agricultor, porém, alicerçada no seu papel informativo e de orientação na perspectiva da conscientização dos seus direitos, deveres e do real papel das associações enquanto entidades que devem garantir autonomia, autogestão e, concomitantemente, a emancipação dos sujeitos envolvidos,

Portanto, mesmo cercada de instabilidades, é correto afirmar que a relação entre agricultura familiar e associativismo se torna significativa, uma vez que essa prática tem viabilizado positivas mudanças na vida do agricultor familiar e no espaço rural brasileiro, mediante a importantes conquistas que geram relações de produção, culturais, comercialização e também de ações políticas e sociais.

\section{Referências}

ABRAMOVAY, Ricardo. Agricultura familiar e uso do solo. São Paulo em Perspectiva - Abr/jun, vol. 11, n²:73-78, 1997. Disponível em:

<ricardoabramovay.com/agricultura-familiar-e-uso-do-solo/>. Acesso em: 07 de mar. de 2017.

Paradigmas do Capitalismo Agrário em Questão. 3 ed. São Pulo: EDUSP 2007.

ParaOnde!?, Porto Alegre, v.11, n.1, p.17-28, 2019. http://seer.ufrgs.br/paraonde

Edição Especial: "Geografia e transformações socioespaciais: dinâmicas agrárias e políticas do desenvolvimento regional" 
BESERRA, Maria dos Remédios. ASSOCIATIVISMO RURAL: estratégia de participação para consolidação da agricultura familiar na Associação Comunitária dos Pequenos Produtores Rurais de Mirolânia, em Picos - Piauí. 87 p. Recife, 2011. Disponível em:

< https://repositorio.ufpe.br/handle/123456789/9292>. Acesso em: 07 de mar. de 2017.

BRASIL. MDA. Plano safra da agricultura familiar 2011/2012: para quem gosta de notícias boas, este é um prato cheio. Brasília (DF): MDA, 2013. Disponível em:

< www.ciflorestas.com.br/arquivos/d_d_d_30984.pdf >. Acesso em: 02 de mar. de 2017.

CARVALHO, D. M. Trajetória dp PRONAF em Sergipe: desenvolvimento e mudanças sócio-espaciais. São Cristóvão: Editora UFS, 2018,

GANANÇA, Alexandre Ciconello. Associativismo no Brasil: características e limites para a construção de uma nova institucionalidade democrática participativa. 2006. Dissertação (Mestrado em Ciência Política) Instituto de Ciência Política da Universidade de Brasília - UnB, Brasília, 2006. Disponível em: <repositorio.unb.br/handle/10482/6650?mode=full>. Acesso em: 08 de mar. 2019.

JUNQUEIRA, Clarissa Pereira.; Lima, Jandir Ferrera de. Políticas públicas para a agricultura familiar no Brasil. Semina: Ciências Sociais e Humanas., Londrina, v. 29, n. 2, jul./dez. 2008. p. 159-176. Disponível em:

<www.uel.br/revistas/uel/index.php/seminasoc/article/download/5469/4991>. Acesso em: 20 de mai. de 2017.

LISBOA, A. S; ALCANTARA, F. V. Espaço Rural e e Associativismo no Fortalecimento aa Agricultura Familiar. VII SINGA, 2015.

MATTEI, L. Impactos do Pronaf: análise de indicadores. Brasília: Ministério do Desenvolvimento Agrário, Núcleo de Estudos Agrários e Desenvolvimento Rural, 2005.

OLDADE, A. R; PORTUGAL, C. A. Agricultura Familiar, Reforma Agrária e sua inserção no enfoque territorial no Brasil. P. 1-18, 2011.

OLIVEIRA, Adriano Rodrigues de Antonio; HESPANHOL, Nivaldo. $O$ Associativismo $e$ o desenvolvimento territorial rural do Pontal do Paranapanema-SP. s/d.

PANZUTTI, N; MONTEIRO, A. V. Agricultura Familiar e Políticas Públicas. Cadernos Ceru v. 25, n. 2, 06, 2015.

PICOLOTTO, E. L. As Mãos que Alimentam a Nação: agricultura familiar, sindicalismo e política. 289 f., 2011.

RUA, M. G. Análise de políticas públicas: conceitos básicos. Rio de Janeiro, 2005. Curso de Aperfeiçoamento em Agroecologia. REDCAPA - Rede de Instituições Vinculadas à Capacitação em Economia e Política Agrícola da América Latina e Caribe.

SCHNEIDER, Sergio; NIEDERLI, P. André. Agricultura Familiar e Teoria Social: a diversidade nas formas familiares de produção na agricultura. Savan: desafios e estratégias para o equilibro entre sociedade, agronegócio e recursos naturais, cap. 32, p . 988-1014, s/d. Disponível em:

$<$ http://www.ufrgs.br/pgdr/publicacoes/producaotextual/sergio-schneider/schneider-s-e-niederle-p-aagricultura-familiar-e-teoria-social-a-diversidade-das-formas-familiares-de-producao-na-agricultura-infaleiro-f-g-e-farias-neto-a-1-ed-savanas-desafios-e-estrategias-para-o-equilibrio-entre-sociedadeagronegocio-e-recursos-1>. Acesso em: 05 de mai. de 2017.

Para0nde!?, Porto Alegre, v.11, n.1, p.17-28, 2019. http://seer.ufrgs.br/paraonde

Edição Especial: "Geografia e transformações socioespaciais: dinâmicas agrárias e políticas do desenvolvimento regional" 
SILVA, S. P. Políticas públicas, agricultura familiar e desenvolvimento territorial: uma análise dos impactos socioeconômicos do Pronaf no território médio Jequitinhonha - MG. IPEA, Brasília, jan. 2012. Disponível em:

< http://repositorio.ipea.gov.br/bitstream/11058/1013/1/td_1693.pdf>. Acesso em: 07 de mar. de 2019.

SPERRY, Suzana, CARVALHO Júnior, Carlos H. T. \& MERCOIRET, Jacques. Ações coletivas praticadas pelos produtores rurais. Distrito Federal: Embrapa, 2003. 150 p.

TONIASSO, H. R. Agricultura Familiar e Associativismo Rural - o caso associação harmonia de agricultura familiar de mato grosso do sul e a sua sustentabilidade. Informe Gepec - Vol. 12, $\mathrm{n}^{\mathrm{o}} 2$, jul/dez. 2007. Disponível em:

< e-revista.unioeste.br/index.php/gepec/article/view/1323>. Acesso em: 11 de mai. de 2017. 